\title{
KIT NM_000222.2:C.2458G>T
}

National Cancer Institute

\section{Source}

National Cancer Institute. KIT NM 000222.2:C.2458G>T. NCI Thesaurus. Code C155701.

A nucleotide substitution at position 2458 of the coding sequence of the KIT gene where guanine has been mutated to thymine. 